\title{
BIOLOGICAL ASPECTS OF THE TORTOISE BEETLE, CASSIDA \\ VITTATA VILL., ( COLEOPTERA: CHRYSOMELIDAE) AS AFFECTED BY FEEDING ON DIFFERENT SUGAR BEET VARIETIES
}

\author{
EL-SERWY, S. A. \\ Plant Protection Research Institute, ARC, Dokki, Giza \\ (Manuscript received 4 September 2008)
}

\begin{abstract}
Effect of feeding the tortoise beetle, C. vittata Vill., females emerged from diapause (FED) and larvae on different sugar beet varieties on its reproductive capacity, oviposition period, incubation period \& hatchability of eggs and the duration periods of larval and pupal stages were studied from February to August 2006. Results showed that the highest reproductive capacity ( $263 \pm 68$ eggs per female), the longest oviposition period ( $62 \pm 15.8$ days) and the highest feeding pores (10.6 \pm 1 feeding pores /day ) were recorded on Dema poly variety under laboratory conditions of $22.7 \pm 4.1 \mathrm{C}^{\circ}$ and $42.7 \pm 6.8 \%$ R. H. There are significant differences when compared to Toro, Monte blanco and both varieties, respectively. Dema poly was the most preferred variety for oviposition and feeding. Feeding females or larvae on different sugar beet varieties had no significant effect on the incubation period and hatchability rate of eggs as well as the duration periods of larva and pupa. $C$. vittata has a single generation in a year. The ovipositional activities by (FED) and active females started in mid February and April and prolonged until late March and June, respectively. Its reproductive capacities were $213.3 \pm 10$ eggs per (FED) and $141.7 \pm 25.3$ eggs per active female fed on Monte blanco variety and the difference was significant, but $106.3 \pm 60.6$ eggs per female collected from the field was recorded when fed on the same variety during the period of active females. Active adults entered diapause by July which ceased for laying eggs and feeding, but not continued to over the winter which died under hot and dry conditions during August. Females lived longer than males where the averages of life span and life cycle were $110.9 \pm 12.1 \& 92.7 \pm 8.6$ and $147.4 \pm$ $17.2 \& 129.2 \pm 15.5$ days, respectively.
\end{abstract}

\section{INTRODUCTION}

Since the grandiose efforts to change multi-tillering wild forms of Beta vulgaris L. into high- productive hybrids with a single tiller and profitable crop number of herbivorous insects adapted to feeding on this crop Fedorenko, 2006. Willcocks (1924) reported that the tortoise beetle , C. vittata Vill., was found in small numbers in 1918 by Alfieri feeding on the leaves of the Egyptian chard or leaf-beet, Beta cicla. It became a very injurious and serious pest since invading the commercial sugar beet, Beta vulgaris L., plants in 1971 at Alexandria, Egypt (Hammad el al, 1980). Several authors contributed to survey the diapuse sites, biological aspects of the different 
stages, life span and oviposition of C. vittata in Egypt (Abo-Aiana, 1991; Awadalla, 1991; Bassyouny \& Maareg,1992; El-Khouly, 1992, Mohamed, 1995; Abdel-Raheem, 2000 and Abo El-Naga,2004. It had a single generation occurring during March / May on sugar beet plantations and diapausing adults were found among wild vegetations or dense crops like sugar cane in Morocco and Egypt (Laraichi et al, 1984 and Salama \& Elnagar, 1992).

This work aimed to study some biological aspects of $C$. vittata as affected by: feeding adults emerged from diapause (AED) or rearing larvae on different sugar beet varieties and adults statues of (AED) or active (reared) (AA) compared to those collected from infested fields (ACF) at Shirbin in Daqahlyia governorate which fed on Monte blanco sugar beet variety under laboratory conditions during February- August 2006.

\section{MATERIALS AND METHODS}

To maintain the food supply of the experimental adults: three sugar beet, Beta vulgaris L., varieties; Dema poly, Toro and Monte blanco were planted in three replicates on September 25 in light infestation area at Bila in Kafr El-Sheikh governorate in 2005. Twenty leaves were collected randomly from each plot at weekly interval from February 7 to May 23, 2006. However, C. vittata adults emerged from diapause (AED) were randomly collected from untreated sever infested sugar beet fields at Shirbin in Daqahlyia governorate during February- May 2006.

\section{1- Assessment the reproductive capacity and oviposition period as affected by}

\section{1-1 Feeding females from diapause (FED) on different sugar beet varieties}

To assess the impact of feeding (FED) on different sugar beet varieties: adult (females and males) of $C$. vittata were kept in a petri dish $(10 \mathrm{~cm}$., in diameter) and were fed daily on Dema poly, Toro and Monte blanco leaf pieces. Each variety contained 3 and 5 replicates on February 19 and 26 in 2006, respectively. Daily deposited eggs and feeding pores on each leaf piece of the different varieties were recorded and changed by fresh one until the adults died.

\section{1-2Females statues}

\section{1-2-1 Females emerged from diapause}

To assess the reproductive capacity of (FED): three pairs (females and males) of $C$. vittata adults were collected on February 7, 2006. Each pair were kept in a petri dish $(10 \mathrm{~cm})$ provided with a leaf piece of Monte blanco sugar beet variety. Deposited eggs on both sides of the leaf piece were recorded and changed daily with a fresh leaf 
piece of Monte blanco variety and replaced by forage beet during June until all individuals died.

\section{1-2-2 Active (reared) females (AF)}

To assess the reproductive capacity of (AF): thirty six adults (females and males) reared from Monte blanco variety were emerged during March 21- April 30, 2006. Each pair were kept singly in a petri dish $(10 \mathrm{~cm})$ in six replicates during $21-30$ March, 13-22 and 24-30 April in 2006. Deposited eggs on the leaf piece were recorded and changed daily with a fresh leaf piece of Monte blanco variety and replaced by forage beet during June until adults died.

\section{1-3 Females collected from infested fields (FCF) during the sugar beet growing season}

To determine the potential reproduction and ovipositional period of (FCF) during the sugar beet growing season: ten adults (females and males) were randomly collected at two weekly interval from March, 26 to May, 21. Daily inspection was made; laid eggs were recorded as well as insects were provided with fresh a fresh leaf piece of Monte blanco variety and replaced by forage beet during June until adults died.

\section{2- Assessment of the duration periods of the immature stages as affected by}

\section{2-1 Feeding (FED) on different sugar beet varieties}

To study the impact of feeding of (FED) on different sugar beet varieties on incubation period and hatchability of eggs: daily deposited eggs by females fed on Dema poly, Toro and Monte blanco sugar beet varieties were counted.. Sixty eggs on the leaf pieces of each variety were placed in petri dishes $(10 \mathrm{~cm}$, each) at weekly interval from February 20 to March 26, 2006. Daily examination was made and the newly hatched larvae were counted. To assess the duration of larvae on each variety: every 5 newly hatched larvae were reared in a petri dish $(10 \mathrm{~cm})$ on the leaf pieces of each sugar beet variety in five replications weekly. Pupae transferred into petri dishes $(5 \mathrm{~cm})$ until adults emerged. Duration of larval and pupal stages were recorded.

\section{2-2 Females statues}

\section{2-2-1 Females emerged from diapause (FED)}

To assess the incubation period and hatchability of eggs (FED) fed on Monte blanco variety: daily deposited eggs on the leaf pieces were counted and placed in a petri dish $(10 \mathrm{~cm})$ of total 100 and 50 at weekly interval from February 8 to March 1 and from 8 to 22 of March 2006, respectively. Daily examination was made and the newly hatched larvae were counted. To assess the duration of larvae: 50 and 25 of the newly hatched larvae were used, respectively. Every 5 newly hatched larvae were reared in a petri dishe $(10 \mathrm{~cm})$ on the leaf pieces of Monte blanco sugar beet variety until pupation. Pupae transferred into petri dishes $(5 \mathrm{~cm})$ until adults emerged. Duration of larval and pupal stages were recorded. 


\section{2-2-2 Active (reared)females (AF)}

To assess the incubation period and hatchability of eggs by (AF) from Monte blanco variety: hundred deposited eggs on the leaf pieces were counted from 19 to 21 of April 2006 and placed in three petri dishes (10 cm, each). Daily examination was made and the newly hatched larvae were counted. To assess the duration of larvae: 50 of the newly hatched larvae were reared in 10 petri dishes $(10 \mathrm{~cm}$, each). on the leaf pieces of Monte blanco sugar beet variety until pupation. Pupae transferred into petri dishes $(5 \mathrm{~cm})$ until adults emerged. Duration of larval and pupal stages were recorded.

\section{RESULTS AND DISCUSSION}

During the sugar beet growing season 2005-2006: adults of $C$. vittata emerged from diapause appeared in early February and the ovipositional activity by females started at the end of the month in sugar beet fields at Shirbin, but undetected numbers were observed in late March where the same was continued until the end of the sugar beet growing season at Bila.

C. vittata adults often have a metallic coloration, but some of them were green and red. Specimens of these different colors were submitted to identification by Dr. C. S. Chaboo (Division of Invertebrate Zoology, American Museum of Natural History, New York, U. S. A.) in September 2006. She identified them as C. vittata. El-Torkey (2003), reported that colour changing in this species probably is a protective function.

\section{1- The reproductive capacity and oviposition period as affected by}

\section{1-1 Feeding (FED) on different sugar beet varieties}

Under laboratory conditions of $22.7 \pm 4.1 \mathrm{C}^{\circ}$ and $42.7 \pm 6.8 \% \mathrm{R}$. H. the overall general average of deposited eggs, oviposition period and fecundity were $229.7 \pm$ 59.4 (range 144- 366) eggs per female, $47.8 \pm 16.9$ (range 24-84) days and $5.3 \pm 2$ (range 1-22) eggs per day, respectively (Table 1). Feeding (FED) on different sugar beet varieties affected reproduction and oviposition period. Females fed on Dema poly and Monte blanco varieties led higher numbers of eggs than those fed on Toro and the difference was significant at $0.01 \%$ level. Significant interaction existed between variety and experimental date on number of deposited eggs; the highest average $321.7 \pm 38.4$ was recorded by females fed on Dema variety on February 19. The longest and the shortest oviposition periods ranged between 43-84 (average $62 \pm$ 15.8) days and 24-45 (average $36.2 \pm 7.4$ ) days were recorded by females fed on Dema poly and Monte blanco varieties with significant difference at $0.05 \%$ level, but the differences were insignificantly and significantly when compared with those fed on Toro variety, respectively. Feeding females on different varieties had no significant effect on fecundity and ranged between 1-22 (average $5.3 \pm 2$ ) eggs / day. Adults preferred Dema poly variety for feeding than the two other varieties with significant 
differences at $0.05 \%$ level (Table 1 ). Weekly general averages no. of deposited eggs / female and feeding pores / adult are represented in Fig.1 a. Both eggs and feeding pores started in low number about 9 eggs / female or feeding pores / adult in the third week of February at mean of $14.5 \pm 1.5 \mathrm{C}^{\circ}$ and $54.1 \pm 3.6 \% \mathrm{R}$. H., reached a peak about 53 eggs and 77 feeding pores at means of $20 \pm 1.5 \& 16 \pm 2.8 \mathrm{C}^{\circ}$ with $50.5 \pm$ $3.8 \& 44.5 \pm 2.7 \%$ R. H. in the first and the second weeks of March, respectively. Eggs and feeding pores decreased gradually and lowered to less than an egg and about 8 feeding pores at mean of $22.8 \pm 1.1 \& 25.4 \pm 1.4 \mathrm{C}^{\circ}$ with $37 \pm 2.5 \& 34.4$ $\pm 2.4 \% \mathrm{R} . \mathrm{H}$. in the second and the third weeks of May , respectively.

\section{1-2 Females statues}

The reproductive capacity of (FED) fed on Monte blanco variety was higher than (AF) fed on the same variety and the difference was significant at $0.05 \%$ level, but its oviposition periods not varied where the difference was insignificant (Table 2). Deposited eggs and oviposition period of (FED) ranged between 203-223 (average $213.3 \pm 10$ ) eggs per female and 36-47 (average $43 \pm 6.1$ ) days at $20.1 \pm 4.5 \mathrm{C}^{\circ}$ and $45.9 \pm 6.2 \%$ R. H. Such values being in respective ranged between 35-218 (average $141.7 \pm 25.3$ ) eggs per female and 17-71 (average $41.4 \pm 8.5$ ) days in the case of (AF) at mean of $27.2 \pm 3.7 \mathrm{C}^{\circ}$ and $41.5 \pm 5 \% \mathrm{R}$. H. The ovipositional activity by (AF) started after preoviposition period ranged between 13-29 (average $18.1 \pm 2.4$ ) days. Fecundities of (FED) and (AF) not varied and ranged between 1-23 (average $5 \pm 0.5$ ) eggs / day and 1-24 (average $3.7 \pm 0.8$ ) eggs / day, respectively.

\section{1-3 Females collected from infested fields (FCF)}

The reproductive capacity and oviposition period of (FCF) fluctuated greatly according to the collection date. The general average of deposited eggs was $106.3 \pm$ 60.6 (range: 8-230) eggs per female and oviposition period was $33.6 \pm 15.4$ (range 661 ) days at mean of $27.4 \pm 3.8 \mathrm{C}^{\circ}$ and $41.5 \pm 5 \%$ R.H. (Table 2). The highest deposited eggs (average $170.2 \pm 4.4$ ) eggs per female and the longest oviposition period (average $48.6 \pm 7.4$ ) days were attained by the females collected on April 23 at mean of $28.5 \pm 3 C^{\circ}$ and $41.1 \pm 5.4 \%$ R.H. These highest values are significantly varied when compared with those recorded by wild females collected on April 9 or May 21, but not varied than those obtained on May 7 and the differences were insignificant. Fecundities of the collected wild females during late March- the third week of May not varied and the difference was insignificant. It ranged between1-19 (general average $3 \pm 0.5$ ) eggs / day at mean of $27.4 \pm 3.8 \mathrm{C}^{\circ}$ and $41.5 \pm 5 \%$ R.H. (Table 2).

Weekly averages no. of deposited eggs by (FED), (AF) and (FCF) are illustrated in Fig.1.b. Ovipositional activity by (FED) started in high no. of 38 eggs in the second week of February reached a peak of 54 in the next week at means of $13.2 \pm 3.5 \&$ $14.5 \pm 1.5 C^{\circ}$ and $49.5 \pm 5.2 \& 54.1 \pm 3.6 \%$ R. H., respectively. It decreased 
gradually and lowered to 7 eggs in late March at mean of $20.9 \pm 2 \mathrm{C}^{\circ}$ and $47.8 \pm$ $3.9 \%$ R.H. On the same week and two weeks later ovipositional activities by (FCF) and (AF) started in low number about 4 eggs and were continued until late June reached a peak about 17 and 27 eggs in the second and the third weeks of May at means of $22.8 \pm 1.1 \& 25.4 \pm 1.4 \mathrm{C}^{\circ}$ and $37 \pm 2.5 \& 34.4 \pm 2.4 \% \mathrm{R}$. H., respectively.

These results show that the reproductive capacity and oviposition period of $C$. vittata (FED) varied greatly by feeding on different sugar beet varieties. There are significant differences between Dema poly and Toro in number of deposited eggs and Monte blanco in oviposition period, but fecundities not varied among the three varieties. Adults preferred Dema poly variety for feeding than the two other varieties and the difference was significant. The reproductive capacity of (FED) fed on Monte blanco variety was significantly higher than those of (AF) reared from the same variety, whereas the differences between its ovipositional periods and fecundities were insignificant. Under field conditions, the susceptibility of sugar beet varieties to $C$. vittata infestation varied and the highest population density of adults and deposited eggs were recorded on Kewemira sugar beet variety (Awadalla et al, 1992 and Samy et al, 1992). The ovipositional activities by (FED) and (AF) started in the second week of February and after two months and continued until late March and June reached its maximum number in the third week of February and May, respectively. Deposited eggs by (FED) fed on the different sugar beet varieties overlapped with these laid by (AF) during mid April- mid May. The oviposition period of (FCF) prolonged from late March to late June and peaked in mid May. Females collected in the third week of April laid significantly higher eggs than those collected during late March- early April or in the third week of May. As a result, the oviposition period of $C$. vittata females prolonged from mid February to late June with an earlier peak occurred on the third week of February by (FED) collected in the second week of February and late peak in the third week of May by (AF). This result is in agreement with findings obtained by (Abo-Aiana, 1991, and Abo El-Naga, 2004) in sugar beet fields at Kafr El-Sheikh and Tanta.

\section{2-The postoviposition period and longevity as affected by}

\section{2-1 Feeding (FED) on different sugar beet varieties}

Under laboratory conditions of $22.7 \pm 4.1 \mathrm{C}^{\circ}$ and $42.7 \pm 6.8 \%$ R.H. the postoviposition period was insignificantly affected by feeding females on Dema poly, Toro and Monte blanco sugar beet varieties with overall average $20.4 \pm 17.1$ (range 247) days (Table 1). Also, the longevities of females and males fed on these varieties were insignificantly different with overall average $68.2 \pm 23$ (range 36-115) days and $63.5 \pm 20.4$ (range 31-95) days, respectively 


\section{2-2 Females statues}

Active females reared from Monte blanco sugar beet variety suffered longer postoviposion period than (FED) fed on the same variety with significant difference at $0.05 \%$ level (Table 2). It ranged between 18-77 (average $51.4 \pm 9.4$ ) days and 2239 (average $28.3 \pm 9.3$ ) days at means of $27.2 \pm 3.7 \& 20.1 \pm 4.5 C^{\circ}$ and $41.5 \pm 5 \&$ $45.9 \pm 6.2 \%$ R. H., respectively. Whereas, the longevity of both sexes was markedly fluctuated between adults emerged from diapause and active one. Active females and males harbored the longest life span with averages of $110.9 \pm 12.1$ and $92.7 \pm 8.6$ day at mean of $27.2 \pm 3.7 \mathrm{C}^{\circ}$ and $41.5 \pm 5 \%$ R.H. versus to $71.3 \pm 3.2$ and $56.3 \pm$ 7.5 day for those emerged from diapause at mean of $20.1 \pm 4.5 \mathrm{C}^{\circ}$ and $45.9 \pm 6.2 \%$ R. H. with significant difference at $0.01 \%$ level (Table 2 ).

\section{2-3 Females collected from infested fields (FCF)}

The postoviposition period of (FCF) ranged between 13-80 with an overall average of $45.9 \pm 23$ days at mean of $27.4 \pm 3.8 \mathrm{C}^{\circ}$ and $41.5 \pm 5 \% \mathrm{R}$. H. (Table 2) It fluctuated greatly where the longest periods were attained by females collected during April 23- May 7 when compared to those collected early from March 26 to April 9 or late on May 21 and the difference was significant at $0.01 \%$ level (Table 2). Females collected from the field lived longer than males and were significantly different at $0.01 \%$ level (Table 2). The general averages were $79.5 \pm 25.4$ (range35-123) days and $66.1 \pm 27.6$ (range 23-115) days, respectively. Both sexes were varied greatly according to the collection date. The highest and the lowest averages ranged between $100.2 \pm 8.5-109.4 \pm 13$ and $51.6 \pm 10.2-57.4 \pm 8.5$ but was $79 \pm 7.3$ days for females collected during April, 23 - May 7, March 26 - April 9 and May 21 with significant difference at $0.01 \%$ level (Table 2 ). Such averages of males being in respective were $91.4 \pm 6.4-91.8 \pm 20.7,35.8 \pm 3.5-38.2 \pm 14.1$ and $73.2 \pm 5.6$ days with differences at the same level.

These results indicate that the postoviposition period of (AF), (FED) and (FCF) complex fluctuated greatly, but insignificantly affected by feeding females on different sugar beet varieties. The longest postoviposition periods occurred in females exposed to complete darkness than those of continuous light and for females fed on sugar beet when compared to those fed on forage beet (Awadalla, 1991 and El-Khouly, 1992). Generally, the adult females survived longer period than adult males. Similar results were recorded on sugar beet by (Bassyouny \& Maareg, 1992 and Mohamed, 1995). 


\section{3- Duration periods of the immature stages as affected by 3-1 Feeding (FED) and rearing larvae on different sugar beet varieties}

Under laboratory conditions of $20.9 \pm 3.8 \mathrm{C}^{\circ}$ and $45.8 \pm 6.3 \% \mathrm{R}$. H.: the incubation period and hatchability\% of deposited eggs by females fed on different sugar beet varieties were insignificantly affected with general averages of $9 \pm 0.5$ (range 7-11) days and $79.2 \pm 4 \%$ (range 60.1-88.2\%), respectively (Table 3). The same result was obtained for the larval duration as well as pupae duration with general averages of $16.9 \pm 0.3$ (range 15-20) and $8.9 \pm 0.2$ (range 7-12) days, respectively, whereas the total duration period from egg to adult lasted an average of $34.8 \pm 0.4$ (range 29-43) days. The emergence period prolonged from the third week of March to late April reached a peak of 83 adults in mid April.

\section{3-2 Feeding (FED) and (AF) or rearing larvae from Monte blanco variety}

Under laboratory conditions of $19.8 \pm 0.5 \mathrm{C}^{\circ}$ and $46.6 \pm 0.6 \%$ R.H. the incubation period of deposited eggs by (FED) lasted $9.3 \pm 1.4$ (range 7.9-12) days and the average of hatching rate was $81.4 \pm 6.7$ (range 74.7-90.2) \% (Table 4). The duration periods of larval and pupal stages ranged between 15.9-19.3 (average 17.4 \pm 1.3 ) and 8.9-10.9 ( average $9.8 \pm 0.6$ ) days, respectively. The total duration period from egg to adult ranged between 32.7-41.8 (average $36.5 \pm 3.2$ ). Duration period of the developmental different stages was generally shortened by increasing temperature and decreasing relative humidity. The longest averages of egg, larva and pupa were $12 \pm 1$ (range 11-14) days, $19 \pm 1.4$ (range 16-23) days and $10.9 \pm 1.2$ (range 9-14) days were attained at mean of $17.7 \pm 0.6 \mathrm{C}^{\circ}$ and $49.3 \pm 0.7 \% \mathrm{R}$. H. opposite to 7.9 \pm 0.5 (range 7-9) days, $15.9 \pm 1.3$ (range 14- 17) day and $8.9 \pm 0.7$ (range 8-10) days were recorded at mean of $22.7 \pm 0.3 \mathrm{C}^{\circ}$ and $42.7 \pm 0.8 \% \mathrm{R}$. $\mathrm{H}$. The total duration periods being in respective were $41.8 \pm 1.3$ (range 39.2-43.1) days and 32.7 \pm 1.6 (range 30.3-33.7) days.

Under hot and dry conditions of $24.1 \pm 0.4 \mathrm{C}^{\circ}$ and $37.7 \pm 0.7 \% \mathrm{R}$. H., the incubation period and hatchability of deposited eggs by (AF) ranged between 5-7 (average $5.5 \pm 0.7$ ) days and 68.2-78.6\% (average $72.5 \pm 5.4$ ) \% (Table 4). Also, the duration of larva and pupa ranged between 11-19 (average 14.4 \pm 2.3 ) days and 5-9 (average $5.7 \pm 1.1$ ) days, respectively, whereas the total duration period (eggadult) ranged between 21-30 (average $25.6 \pm 2.3$ ) days.

These results indicate that females or larvae fed on different sugar beet varieties had no significant effect on the duration periods of the different stages, but its periods shortened by increasing temperature and decreasing relative humidity. El-Khouly (1992), reported that the developmental periods of the different stages varied between sugar beet, forage and chard host plants. 


\section{DISCUSSION}

The reproductive capacity and oviposition period of (FED) as well as the daily feeding pores fluctuated greatly as a result of feeding on different sugar beet varieties. Females fed on Dema poly variety harbored the highest number of deposited eggs and the longest oviposition period than on Toro and Monte blanco varieties with significant differences, respectively. Adults preferred Dema poly variety for feeding than the two other varieties with significant differences. However, fecundity and incubation period \& hatchability of eggs were insignificantly affected by feeding females on different sugar beet varieties, also. The duration periods of both larvae and pupae as well as longevity of females and males were insignificantly affected by rearing larvae on all varieties. Feeding (FED) and (AF) on Monte blanco had no significant effect on fecundity, whereas (FED) laid significantly higher eggs than active one. The tortoise beetle, $C$. vittata, had an annual generation on sugar beet. The ovipositional activities by (FED) and (AF) fed on Monte blanco variety started in mid February and after two months, continued until late March and June and peaked in the third week of February and May, respectively. Deposited eggs by (FED) fed on different sugar beet varieties overlapped with laid by active one during mid April - mid May The total duration period of the developmental stages from egg to adult lasted an average of $34.8 \pm 0.4$ day. The first emergence of active adults started in the third week of March and continued until late April. Active females deposited their eggs after preoviposition period of an average of $18.1 \pm 2.4$ day. Diapaused adults disappeared under sugar beet leaf pieces without feeding and females ceased to laid their eggs and not completed its life cycle and died under the hot and dry conditions at mean of $32 \pm 2.3 \mathrm{C}^{\circ}$ and $48 \pm 3.8 \%$ R.H during August. Females lived longer than males where the averages of life span and life cycle were $110.9 \pm 12.1 \& 92.7 \pm 8.6$ and $147.4 \pm 17.2 \& 129.2 \pm 15.5$ days, respectively . In summer, obligatory diapause of $C$. vittata adults began in June and continues over the winter despite the availability of the sugar beet food plant (Hilal et al, 1983). In Egypt and Morocco, it has a single generation a year and diapausing adults were found among wild vegetations or dense crops like sugar cane (Laraichi et al, 1984; Awadalla, 1991 and Salama \& Elnagar, 1992).

\section{ACKNOWLEDGEMENT}

The author wish to thank Dr. C. S. Chaboo ( Division of Invertebrate Zoology, American Museum of Natural History, New York, U.S. A.) for confirmation of $C$. vittata. 
900 BIOLOGICAL ASPECTS OF THE TORTOISE BEETLE, CASSIDA VITTATA VILL., ( COLEOPTERA: CHRYSOMELIDAE) AS AFFECTED BY FEEDING ON DIFFERENT SUGAR BEET VARIETIES

Table 1 
EL-SERWY, S. A.

Table 2 
902 BIOLOGICAL ASPECTS OF THE TORTOISE BEETLE, CASSIDA VITTATA VILL., ( COLEOPTERA: CHRYSOMELIDAE) AS AFFECTED BY FEEDING ON DIFFERENT SUGAR BEET VARIETIES

Table 3 
EL-SERWY, S. A.

Table 4 


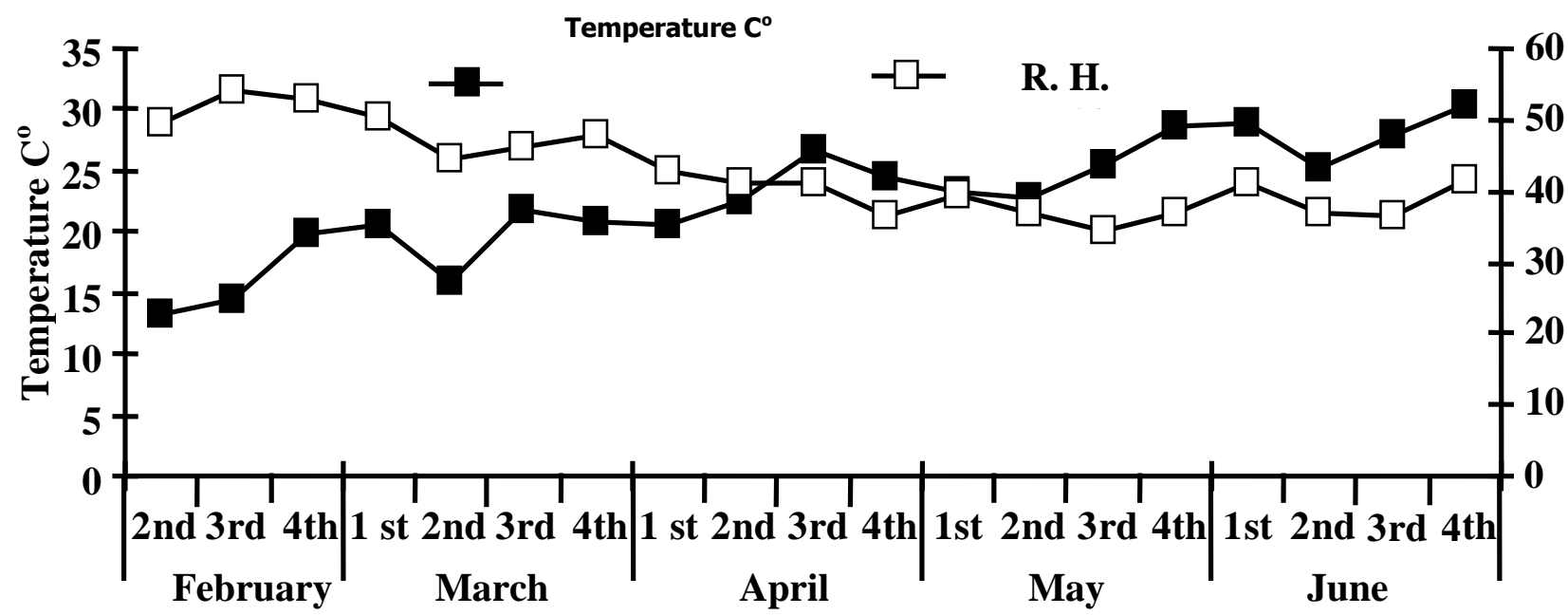

Weeks

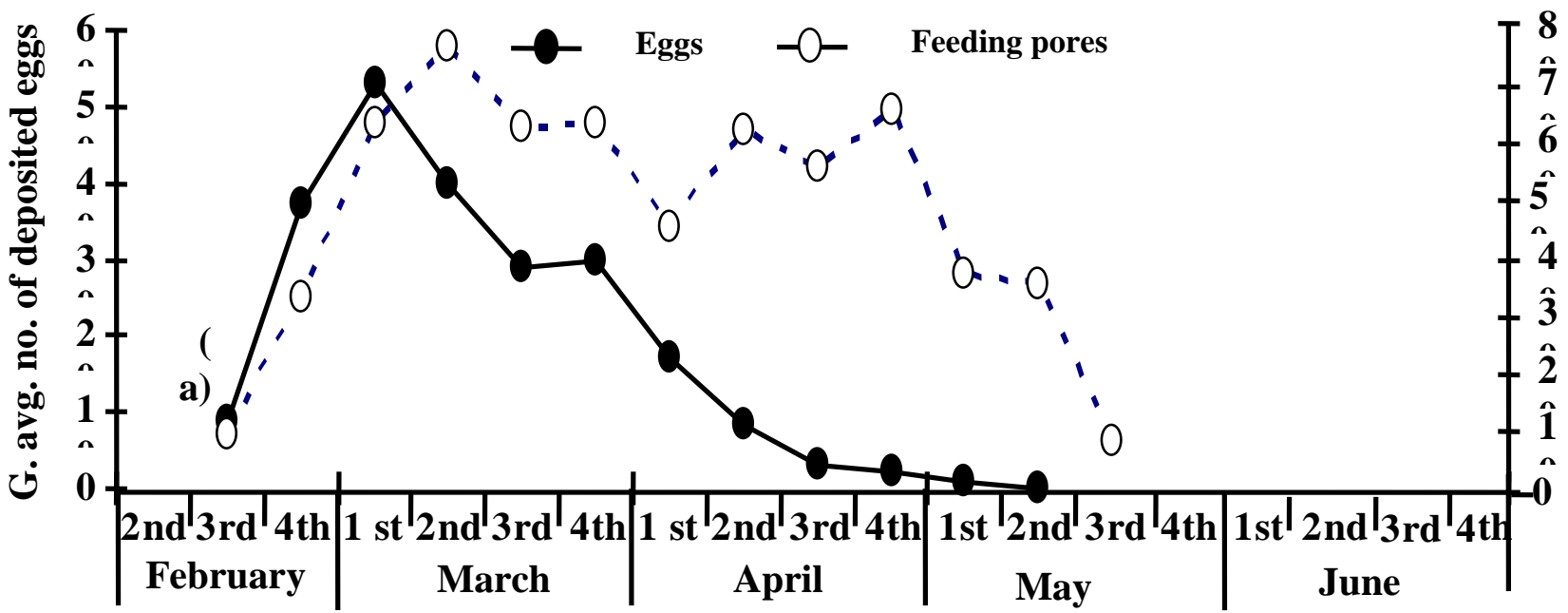

Weeks

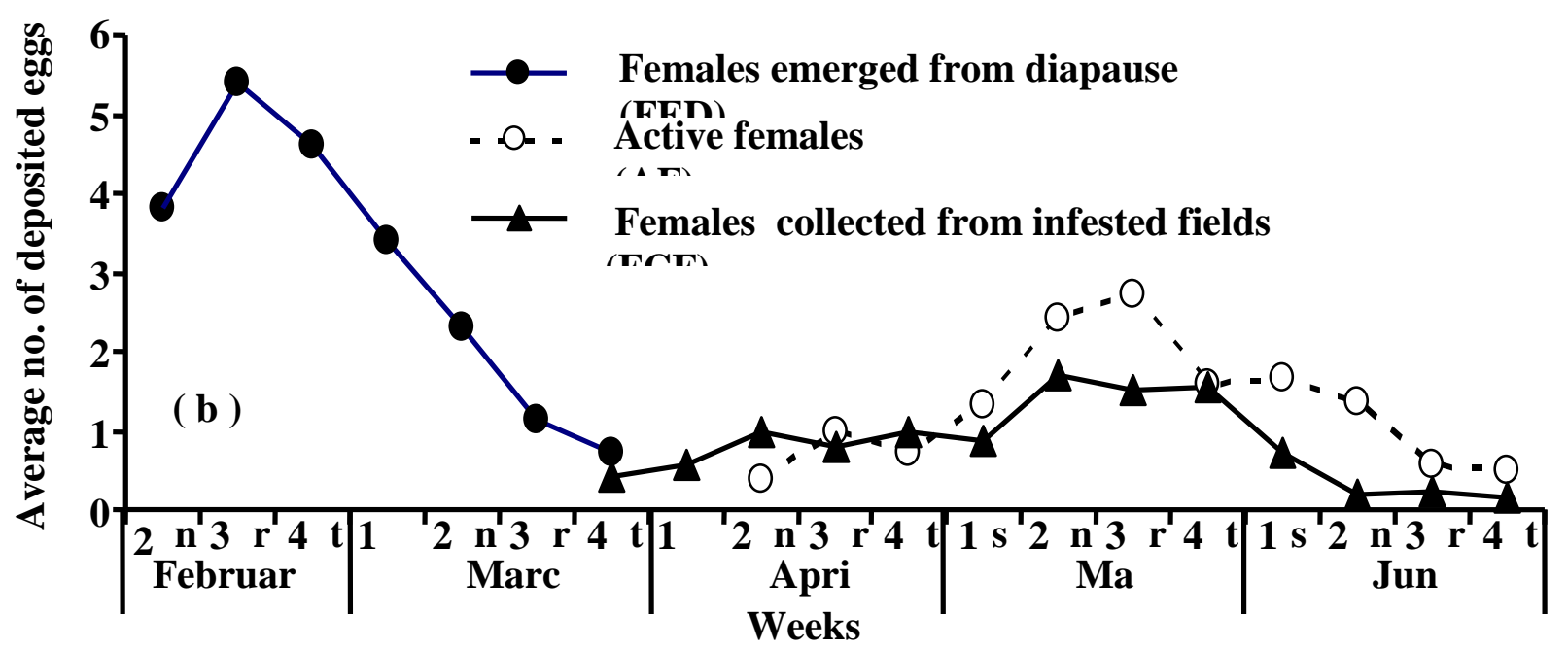

Fig.1. Weekly general average no. of deposited eggs per female and feeding pores per adult on different sugar beet varieties ( a ) and average no. of deposited eggs by active females (AF) of $C$. vittata and those emerged from diapause (FED) or collected from infested fields (FCF) (b) during February- June 2006. 


\section{REFERENCES}

1. Abdel- Raheem, M. A. A. 2000. Ecological and biological aspects of certain key pests of sugar beet in Egypt. M. Sc. Thesis, Fac. of Agric., Cairo Univ., 73 pp.

2. Abo-Aiana, R. A. D. 1991. Studies on pests of sugar beet in Kafr El-Sheikh. Ph. D. thesis, Fac. of Agric., Tanta Univ., 171 pp.

3. Abo El-Naga, A. M. M. 2004. Ecological studies and integrated control of the sugar beet beetle, C. vittata de Villers. M. Sc. Fac. of Agric., Tanta Univ., 129 pp.

4. Awadalla, S. S. 1991. Effect of photoperiod on the adult diapause and developmental stages of the tortoise beetle $C$. vittata Vill. (Coleoptera: Chrysomelidae). Alex. Sci. Exch. 12. no. 2: 47- 58.

5. Awadalla, S. S. , M. E. Ragab and L. A. El-Batran. 1992. Insect infestation levels of sugar beet plants in relation to varieties and planting dates. J. Agric. Sci. Mansoura Univ., 17 (5): 1121-1126.

6. Bassyouny, A. M. and M. F. Maareg. 1992. Biology and life tables of the sugar beet beetle C. vittata Vill. (Coleoptera: Chrysomelidae). Annals of Agric. Sc. Moshtohor. Vol. 30 (1):571- 580.

7. El-Khouly, M. I. I. 1992. Biological study on tortoise beetle C. vittata Viller attacking sugar beet crop. M. Sc. Thesis, Fac. of Agric., Al-Azhar Univ., 122 pp.

8. El-Torkey, A. M. A. 2003. Taxonomic studies on some species of family Chrysomelidae (Order: Coleoptera) in Egypt. Ph D Thesis, Fac. of Sci., Al-Azhar Univ., 302 pp.

9. Fedorenko, V. P. 2006. The most important sugar beet pests in Ukraine and integral measures for their control. Proc.Nat. Sci. Matica Srpska Novi. Sad. 110: 21-38.

10. Hammad, S. M., I. A. Gaaboub and H. A. Akel. 1980. The main properties on sugar beet plants at different planting dates, in relation to pests infestation under the Egyptian conditions. Z. ang. Ent 90: 434-438.

11. Hilal, A., M. Laraichi and F. Hamdaoui. 1983. Demonestration of a state of obligatory diapause in C. vittata Vill. (Coleoptera: Chrysomelidae). Comptes Rendus Hebdomadaires des Séances de l'Académie des Sciences, III. 296 (13): 609-610.

12. Laraichi, M., A. Hilal and F. Hamdaoui. 1984. Biological study on the small green tortoise beetle $C$. vittata Vill. In the Gharb region. Actes de l'Institut Agronomique et Veterinaire Hassan II. 4 [ 1 Numero Special Zoologie)]: 87-92. 
906 BIOLOGICAL ASPECTS OF THE TORTOISE BEETLE, CASSIDA VITTATA VILL., ( COLEOPTERA: CHRYSOMELIDAE) AS AFFECTED BY FEEDING ON DIFFERENT SUGAR BEET VARIETIES

13. Mohamed, A. A. A. 1995. Studies on the sugar beet insect C. vittata Vill. (Coleoptera: Chrysomelidae) in Egypt. M. Sc. Thesis, Fac. of Agric., Alexandria Univ.,170 pp.

14. Salama, R. A. K. and S. Elnagar. 1992. The tortoise bettle, C. vittata Vill. (Coleoptera: Chrysomelidae), a possible pest of sugar beet plantations in Egypt. J. Appl. Ent., 113: 88-92.

15. Samy, M. A. E., K. A. A. Draz and M. H.M. El-Khawalka. 1992. Seasonal fluctuation of $C$. vittata and Pegomyia mixta and their predators in certain sugar beet varieties plantations at Sakha, Egypt. J. Agric. Sci., Mansoura Univ., 17 (9): 3059- 3064.

16. Willcocks, F. C. 1924. A survey of the more important and economic insects and mites of Egypt. Sultanic Agr. Soc. Cairo. Tech. Sect. Bull. 1: 482 pp. 


\title{
تأثر الجوانب الحيوية لخنفساء البنجر السلحفائية \\ بتغذية الكاملات على أصناف البنجر المختلفة
}

\author{
سمير عوض السروى \\ معهز بحوث وقاية النباتات- مركز البحوث الزراعية- دقي- جيزة
}

درس تأثثر تغذية أنات خنفساء البنجر السلحفائية, C. vittata Vill , الخارجة من السكون

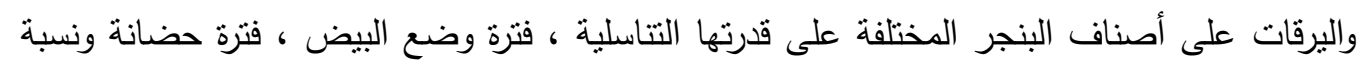

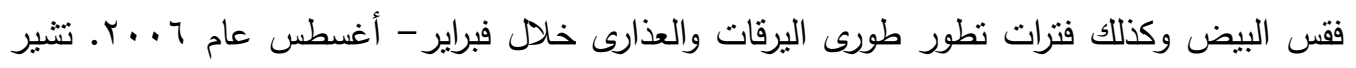

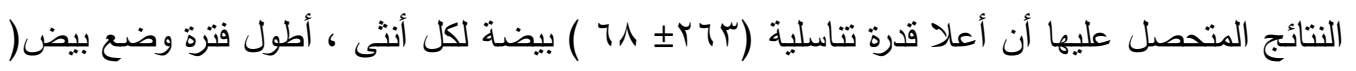
r

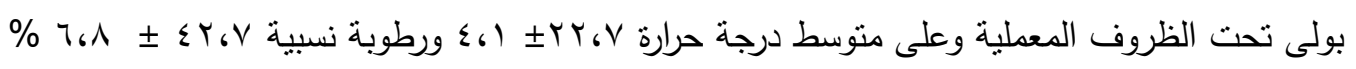
• وجد فروق معنوية مقارنة بالصنف تورو، ومونتى بلانكو وكلا الصنفين، على التوالي. كما أنة ألأكثر

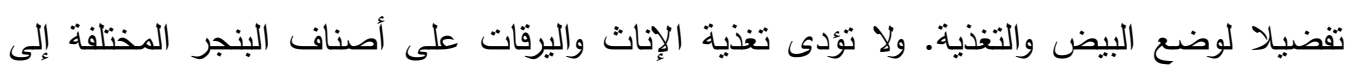

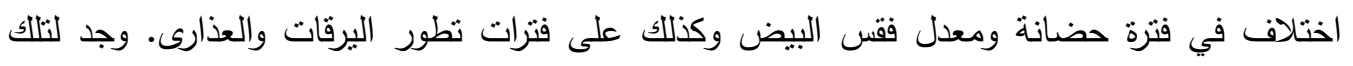
الخنفساء جيل واحد في العام. يبدأ نشاط وضع البيض للإناث الخارجة من السكون وكذلك النشطة في فئري

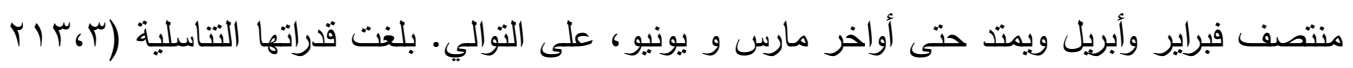

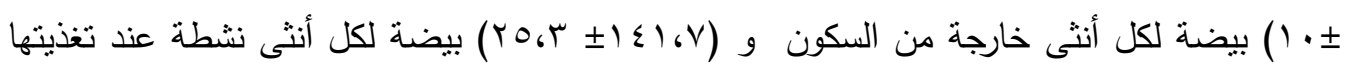

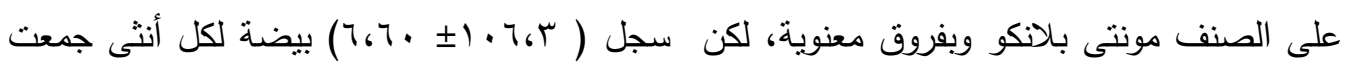

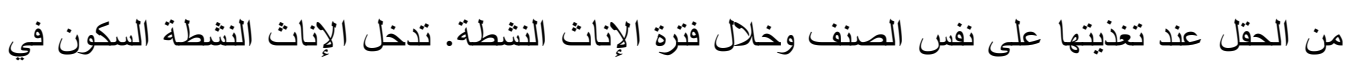

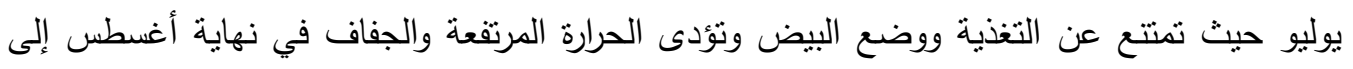

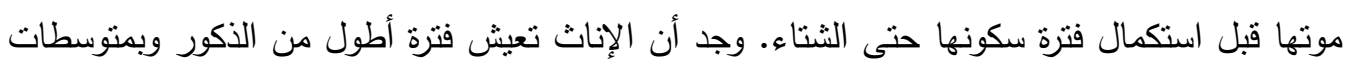

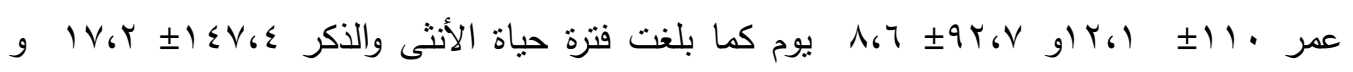

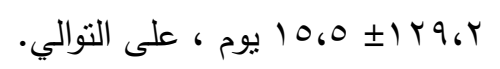

